\title{
Are torque values of preadjusted brackets precise?
}

\author{
Alessandra Motta STREVA¹, Flávio Augusto COTRIM-FERREIRA², Daniela Gamba GARIB³ ${ }^{3}$ Paulo Eduardo Guedes \\ CARVALHO ${ }^{2}$
}

\begin{abstract}
1- DDS, MSc, Visiting Professor, Department of Orthodontics, Dental School, University of São Paulo, São Paulo, SP, Brazil.
2- DDS, MSc, PhD, Professor, Department of Orthodontics, Dental School, University of São Paulo, São Paulo, SP, Brazil.

3- DDS, MSc, PhD, Assistant Professor, Department of Pediatric Dentistry, Orthodontics and Community Health, Bauru School of Dentistry, University of São Paulo, Bauru, SP, Brazil.
\end{abstract}

Corresponding address: Dr. Alessandra Motta Streva - Rua 40, n²0 - sala 517 - Shopping 33 - Torre I - Vila Santa Cecília - Volta Redonda, RJ - Brasil 27260-200 - Phone: +55-24-3342-4227 - e-mail: amstreva@yahoo.com.br

Received: May 24, 2009 - Modification: July 28, 2009 - Accepted: February 16, 2010

\section{ABSTRACT}

\begin{abstract}
bjective: The aim of the present study was to verify the torque precision of metallic brackets with MBT prescription using the canine brackets as the representative sample of six commercial brands. Material and Methods: Twenty maxillary and 20 mandibular canine brackets of one of the following commercial brands were selected: 3M Unitek, Abzil, American Orthodontics, TP Orthodontics, Morelli and Ortho Organizers. The torque angle, established by reference points and lines, was measured by an operator using an optical microscope coupled to a computer. The values were compared to those established by the MBT prescription. Results: The results showed that for the maxillary canine brackets, only the Morelli torque $\left(-3.33^{\circ}\right)$ presented statistically significant difference from the proposed values $\left(-7^{\circ}\right)$. For the mandibular canines, American Orthodontics $\left(-6.34^{\circ}\right)$ and Ortho Organizers $\left(-6.25^{\circ}\right)$ presented statistically significant differences from the standards $\left(-6^{\circ}\right)$. Comparing the brands, Morelli presented statistically significant differences in comparison with all the other brands for maxillary canine brackets. For the mandibular canine brackets, there was no statistically significant difference between the brands. Conclusions: There are significant variations in torque values of some of the brackets assessed, which would clinically compromise the buccolingual positioning of the tooth at the end of orthodontic treatment.
\end{abstract}

Key words: Torque. Orthodontic brackets. Cuspid.

\section{INTRODUCTION}

The completely programmed bracket system, created by Andrews ${ }^{1}$ (1989), was designed with the objective of using arches without bends. However, in spite of incorporating ideal torque characteristics in the structure of such brackets, in some cases it is necessary to apply additional or individual torques on some teeth. This would occur due to several factors ${ }^{10,27}$ : mechanical side-effects ${ }^{25}$, morphological differences in the buccal faces of teeth $4,6,9,21,22,26$, changes in the position of the brackets ${ }^{2,16,22,29}$, different methods of bracket manufacturing ${ }^{12,30}$ and orthodontic wires ${ }^{24}$, the play between the wire and the bracket slot $3,4,7,16,24,25$, variations in the bracket designs $^{8}$, properties of the materials constituting the brackets $7,8,11,13,23$ and wires ${ }^{24}$ and differences between the value of the torque informed by the manufacturer and the real value of the torque of the brackets ${ }^{10}$.

The MBT system created by McLaughlin, Bennett and Trevisi ${ }^{17,18}(1989 ; 2002)$ modified the torque on the brackets of incisors, molars and mandibular premolars, so that the clinical goals could be attained with the minimum insertion of bends in the wires, considering the play between the wire and the bracket slot. As regards the canines, brackets with three torque options were made available to professionals. For the maxillary canines, there are two types of brackets, which provide three types of torque: $-70,00$ e +70 and for the mandibular canines, also two types of brackets, providing three options of torque: $-6^{\circ}, 0^{\circ}$ and $+6^{\circ}$.

The aim of this study was to verify the torque precision of MBT brackets using the canine brackets as the representative sample of six commercial 
brands. The canine brackets were selected due to the importance of the appropriate positioning of those teeth at the end of the orthodontic treatment ${ }^{28}$.

\section{MATERIAL AND METHODS}

A sample of 240 metal brackets with $0.022^{\prime \prime} \times 0.028^{\prime \prime}$ slot of MBT prescription was selected (120 maxillary canine brackets with -70 of torque, and 120 mandibular canine brackets with $-6^{0}$ of torque). Six groups were selected, each one composed by 20 brackets of each of the brands commercially available in Brazil: Kirium Line (lot 3420; Abzil, São José do Rio Preto, SP, Brazil); Mini Master Series (maxillary canines lot 1301 and mandibular canines lot 0311; American Orthodontics, Sheboygan, WI, USA); Morelli MBT (maxillary canines lot 695388 and mandibular canines lot 706230; Morelli, Sorocaba, SP, Brazil); Gemini (lot D7120; 3M Unitek, Monrovia, CA, USA), Elite OPTI-MIM MBT (lots 541311 and 541581 of maxillary canines and 541311 and 541587 of mandibular canines; Ortho Organizers, Carlsbad, CA, USA) and Nu-Edge (lot 3014MLH series 6.749.426; TP Orthodontics, La Porte, IN, USA).

The brackets were placed on acrylic plates that served as templates. Holes were made in these plates ( $7 \mathrm{~mm}$ in diameter by $4 \mathrm{~mm}$ deep) and lines were also demarcated to guide positioning of the brackets. To fix the brackets, the holes were filled with starch based modeling clay so that half of the bracket, in profile, would be inserted while the other half would be exposed for the assessment (Figure 1).

After insertion, the brackets were adjusted with a segment of $0.019^{\prime \prime} \times 0.025^{\prime \prime}$ stainless steel wire. This adjustment allowed the proximal profile of the bracket to be parallel to the template base and perpendicular to the optic visor of the microscope. A microscope (Jenalumar; Carl Zeiss, Jena, Thuringia, Germany) was used, coupled to a computer with a Charge Coupled Device (CCD) camera (KP-M1; Hitachi Denshi, Tokyo, Honshū, Japan) and image acquisition board (DT 55 fram grabber; Data Translation, Prague, Czech Republic). The images obtained by the microscope were analyzed in the Global Lab Image software (Data Translation) by a laboratorial technician instructed by the authors. When it was not possible to visualize the images adequately, they were submitted to one of the software filters.

The torque was measured in the images by means of demarcating reference points and lines. Two points were demarcated at the base of the brackets (Figure 2): point B1 (cervical extremity of the bracket base) and point B2 (occlusal extremity). Two points were also demarcated on the slots, at

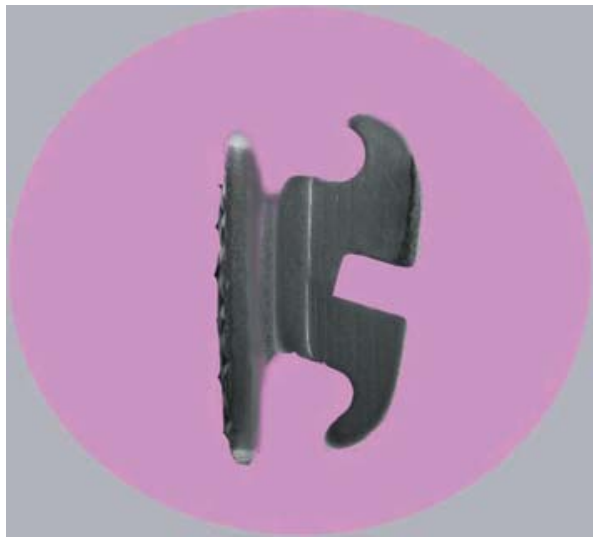

Figure 1- Fixation of the brackets in the template

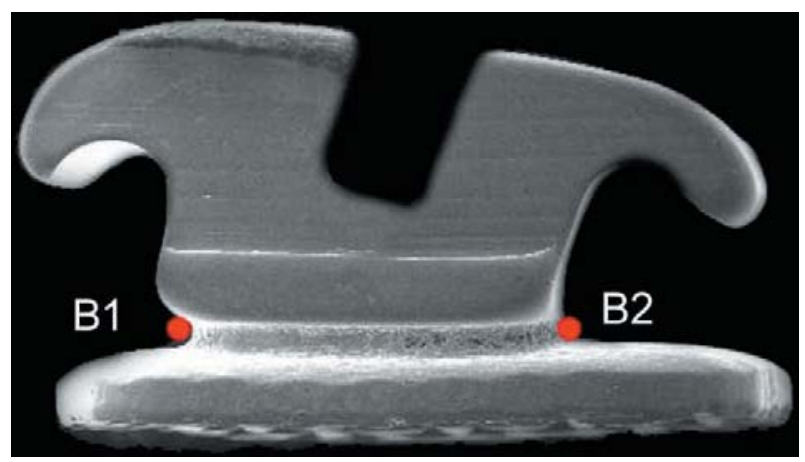

Figure 2- Points B1 and B2

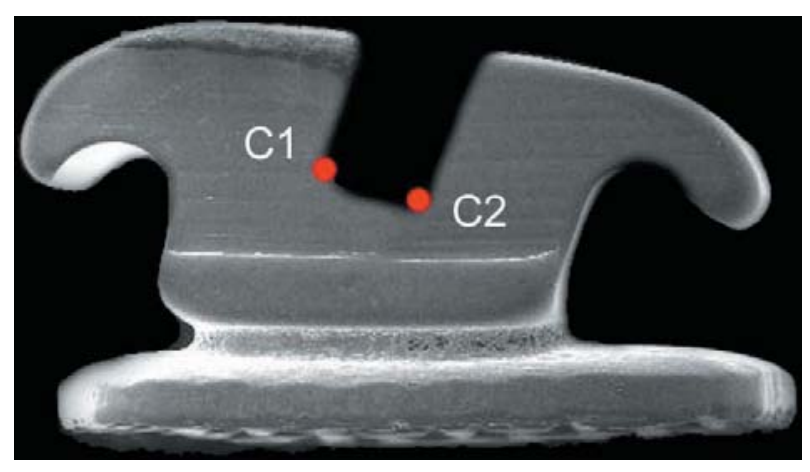

Figure 3- Points $\mathrm{C} 1$ and $\mathrm{C} 2$

Table 1- Descriptive measurements and test of normality for method error (Shapiro-Wilks)

\begin{tabular}{ccccccc}
\hline Group & Median & Mean & SD & $\mathbf{m}$ & $\mathbf{M}$ & $\mathbf{p}^{*}$ \\
\hline 1 & 9.67 & 9.25 & 2.08 & 3.59 & 11.83 & 0.0283 \\
2 & 9.73 & 9.47 & 2.11 & 2.79 & 12.58 & 0.0047 \\
3 & 10.31 & 9.65 & 1.92 & 4.57 & 12.00 & 0.0004 \\
${ }^{*} \mathrm{p}<0.05$ & & & & & & \\
\hline
\end{tabular}

${ }^{*}$ Result of normality test of Shapiro-Wilks

$\mathrm{SD}=$ standard deviation

$\mathrm{m}=$ minimum torque

$\mathrm{M}=$ maximum torque 
the vertex of the angle between the slot floor and the internal face of the wings, denominated $\mathrm{C} 1$ and C2 (Figure 3). If the vertex in question was not clear, due to poor finish of the slot, this point would be defined at the intersection of the angle formed between the line tangential to the internal face of the wing and the line tangential to the floor of the slot. Thus, the two base points defined Line $B$. The floor of the bracket slot, region that receives the orthodontic wire, and therefore, defines the vestibular-lingual inclination (torque) of the teeth in the pre-adjusted techniques, was defined by Line $\mathrm{C}$.

The real torque was then defined by the angle formed between the bracket base (Line B) and the bracket slot floor (Line $\mathrm{C}$ ). The measurements were

Table 2- Descriptive measurements and test of normality for method error (Wilcoxon)

\begin{tabular}{cccc}
\hline Comparison & Mean difference & $\mathbf{p}^{*}$ & Dahlberg \\
\hline $2 \times 1$ & 0.22 & 0.5420 & 0.96 \\
$3 \times 1$ & 0.41 & 0.1187 & 0.80 \\
\hline
\end{tabular}

${ }^{*}$ Result test of Wilcoxon performed in the same software used to obtain the images, with a precision of 0.01 degree.

The Mann-Whitney test was applied to compare mean torque values of each group individually with the prescribed torque value. Mann-Whitney test with Bonferroni correction was used to compare the bracket brands. The casual and systematic error was calculated with Dahlberg formula ${ }^{5}$ and Wilcoxon test, respectively, repeating the measurements of 18 brackets ( 3 brackets of each brand) for 3 times with 1-month interval. The results were considered at a significance level of $5 \%$. The statistics was performed in the $\mathrm{R}$ software version 2.8.2 ( $\mathrm{R}$ Foundation for Statistical Computing, available from http://www.r-project.org, Vienna, Bundesland Wien, Austria).

\section{RESULTS}

\section{Method error}

The results showed no significant systematic error between measurements (Tables 1 and 2). The casual error was less than $1^{\circ}$.

Table 3- Comparison of the mean torque value found for each bracket brand and the prescribed value for maxillary canines and intergroup comparisons

\begin{tabular}{|c|c|c|c|c|c|c|c|}
\hline \multicolumn{8}{|l|}{ Maxillary canines $\left(-7^{\circ}\right)$} \\
\hline Brands & median & mean & SD & m & M & $\mathbf{p}^{*}$ & test $^{* *}$ \\
\hline 3M Unitek & -7.07 & -7.07 & 0.28 & 6.59 & 7.63 & 0.3240 & $a$ \\
\hline Abzil & -7.27 & -7.14 & 0.86 & 5.64 & 9.80 & 0.5754 & $b$ \\
\hline American Orthodontics & -7.35 & -7.18 & 0.49 & 6.19 & 7.81 & 0.1043 & c \\
\hline TP Orthodontics & -6.84 & -6.96 & 0.67 & 5.68 & 8.55 & 0.6274 & $d$ \\
\hline Morelli & -3.02 & -3.33 & 2.33 & 0.61 & 7.63 & $<0.0001$ & $a, b, c, d, f$ \\
\hline Ortho Organizers & -7.06 & -6.97 & 0.38 & 6.28 & 7.60 & 0.8519 & $f$ \\
\hline
\end{tabular}

${ }^{*}$ Compared with the prescription

${ }^{* *}$ Result of the Mann-Whitney test with Bonferroni correction for multiple comparisons, the same letters imply significant difference.

$\mathrm{SD}=$ standard deviation; $\mathrm{m}=$ minimum torque; $\mathrm{M}=$ maximum torque

Table 4- Comparison of the mean torque value found for each bracket brand and the prescribed value for mandibular canines and intergroup comparisons

\begin{tabular}{cccccccc}
\hline $\begin{array}{c}\text { Mandibular canines }\left(-\mathbf{6}^{\mathbf{}}\right) \\
\text { Brands }\end{array}$ & median & mean & SD & m & M & $\mathbf{p}^{*}$ & test $^{* *}$ \\
\hline 3M Unitek & -5.99 & -6.01 & 0.44 & 5.17 & 6.97 & 0.9553 & $\mathrm{a}$ \\
Abzil & -5.98 & -5.89 & 0.55 & 4.82 & 6.91 & 0.4897 & $\mathrm{~b}$ \\
American Orthodontics & -6.33 & -6.34 & 0.39 & 5.58 & 6.91 & 0.0036 & $\mathrm{c}$ \\
TP Orthodontics & -6.18 & -6.22 & 0.78 & 4.65 & 8.87 & 0.0594 & $\mathrm{~d}$ \\
Moreli & -5.94 & -5.50 & 1.62 & 0.42 & 7.44 & 0.3488 & $\mathrm{e}$ \\
Ortho Organizers & -6.38 & -6.25 & 0.41 & 5.28 & 6.77 & 0.0263 & $\mathrm{f}$ \\
\hline
\end{tabular}

${ }^{*}$ Compared with the prescription

${ }^{* *}$ Result of the Mann-Whitney test with Bonferroni correction for multiple comparisons, the same letters imply significant difference

$\mathrm{SD}=$ standard deviation; $\mathrm{m}=$ minimum torque; $\mathrm{M}=$ maximum torque 
Comparison between torque values and established values of MBT brackets

The Morelli brand presented statistically significant differences in comparison to the prescription for the maxillary canine brackets (Table 3). For the mandibular canines, American Orthodontics and Ortho Organizers brackets presented statistically significant differences in comparison to the prescription (Table 4).

\section{Intergroup comparison}

There was a significant difference between Morelli brand and all other brands of the maxillary canine brackets (Table 3). There was no significant difference between the brands for the measurements of mandibular canine brackets (Table 4).

\section{DISCUSSION}

The preadjusted appliance was a great development in orthodontic mechanics. However, preadjustment of brackets to provide torque would be influenced by many factors and among them would be the precision of manufacture by the industry ${ }^{10,12,30}$ The real value of the torque of the brackets should be in accordance with the nominal values informed by the manufacturers ${ }^{10}$. It is important to highlight that there is a lack of studies in the literature analyzing preadjusted bracket precision. Thus, the goal of this study was to perform this verification, by measuring a sample of brackets of various commercial brands. The number of brackets was established by indication of a statistic, so that the number of repetitions would allow for greater reliability of the mathematical tests and would contribute effectively with precise information to orthodontists and manufacturers.

With regard to the methodology, various possibilities were investigated. Some authors that studied orthodontic materials developed mechanical devices to conduct their researches ${ }^{8,19,20}$. Others used computerized systems ${ }^{7}$ or graphic computation systems (CAD) ${ }^{14}$. Nevertheless, optical microscopy was frequently involved $3,6,15,24,30$. In view of this, to measure the torque of the brackets, the precision of the microscope was used in conjunction with digitization and image amplification technology. Thus, there would be precision added to visualization.

For being small parts, orthodontic brackets would be difficult to be handled by the operator. Thus, various templates were tested to handle the brackets, until one of them was as close as possible to the ideal. In principle, the brackets were immersed, in profile, in acrylic resin, but this material did not allow the brackets to be precisely adjusted. Furthermore, some brackets presented better finishing on one proximal surface than on the other, and if they were permanently fixed, it would limit observation to only one of its proximal faces. In view of this, acrylic plates with orifices filled with modeling clay were chosen as the template. Modeling clay was chosen as the method of fixation because of presenting an adequate consistency and less variation to thermal stimuli. The brackets were inserted in this template in profile, and adjusted so that the proximal surface would be parallel to the template base. Thus, the microscope would capture the image correctly. The real torque was then defined by the angle formed between the bracket base (Line B) and the bracket slot floor (Line $\mathrm{C}$ ). The determination of the lines $B$ and $C$ was established by the current manufacture of brackets, which uses computer graphics (CAD) and computer systems $(C A M)^{18}$. Table 3 shows the comparison between the torque values found and the MBT prescription values. Regarding the maxillary canines, it was found that Morelli brand presented statistically significant difference in relation to the expected torque value of -70 . For the mandibular canines (Table 4), it was found that American Orthodontics and Ortho Organizer brands presented statistically significant difference in relation to the expected torque value of $-6^{\circ}$, but with good means, in addition to low amplitudes, and therefore showed manufacturing standardization.

The comparison among the six commercial brands is shown in Tables 3 and 4. Statistically significant differences were found only for the brackets of maxillary canines. In Tables 3 and 4, for the maxillary canines, Mann-Whitney test with Bonferroni correction shows that the Morelli brand differed significantly from the other brands.

By the careful choice of material for this research, and by means of a methodology that allowed excellent visualization and measurement of the angles of torque, it was found that there is still a great deal to improve in the manufacture of these accessories. Few brands met the desired level of standardization. If the brackets do not present a high level of precision, there would be no reason for the orthodontist to use brackets with pre-adjustments in daily clinic. It is obvious that a good professional will know how to make additional bends in the wires, when they are required to improve the tooth positioning. However, Lawrence Andrews $^{1}$ (1989) and Mc Laughlin, Bennett and Trevisi $^{18}$ (2002) conducted studies to establish angles in the brackets in order to modernize and optimize the day-to-day clinic. Therefore, bends in the wires could be minimized if good materials were available to clinicians. It is believed that this study may warn orthodontists, and thus provide stimulus for improvements in the industrial sector. It is also hoped that further research involving orthodontic materials are conducted so that this consciousness raising becomes accentuated. 


\section{CONCLUSION}

Based on the results of this study and in accordance with the sample and the methodology used, it may be concluded that in general, the mean torque values for the brackets were found to be within the values prescribed by the MBT technique, except for the Morelli brand for the maxillary canine brackets. The American Orthodontics and Ortho Organizers presented significant differences for the mandibular canine brackets. The Morelli brand presented significant differences from all the other brands regarding the torques found in the maxillary canine brackets.

\section{REFERENCES}

1- Andrews LF. Straight wire - the concept and the appliance. San Diego: L.A. Wells; 1989. 407 p.

2- Balut N, Klapper L, Sandrik J, Bowman D Variations in bracket placement in the preadjusted orthodontic appliance. Am J Orthod Dentofacial Orthop. 1992;102:62-7.

3- Cash AC, Good SA, Curtis RV, McDonald F. An evaluation of slot size in orthodontic brackets - are standards as expected? Angle Orthod. 2004;74:450-3.

4- Creekmore TD, Kunik RL. Straight wire: the next generation. Am J Orthod Dentofacial Orthop. 1993;104:8-20.

5- Dahlberg G. Statistical methods for medical and biological students. New York: Interscience; London: George Aleen \& Unwin; 1940.

6- Dellinger EL. A scientific assessment of the straight-wire appliance. Am J Orthod. 1978;73:290-9.

7- Fischer-Brandies H, Orthuber W, Es-Souni M, Meyer S. Torque transmission between square wire and bracket as a function of measurement, form and hardness parameters. J Orofac Orthop. 2000;61:258-65.

8- Flores DA, Choi LK, Caruso JM, Tomlinson JL, Scott GE, Jeiroudi MT. Deformation of metal brackets: a comparative study. Angle Orthod. 1994;64:283-90.

9- Germane N, Bentley B, Isaacson RJ, Revere JH Jr. The morphology of canines in relation to preadjusted appliances. Angle Orthod. 1990;60:49-54.

10- Gioka C, Eliades T. Materials-induced variation in the torque expression of preadjusted appliances. Am J Orthod Dentofacial Orthop. 2004;125:323-8.

11- Gmyrek H, Bourauel C, Richter G, Harzer W. Torque capacity of metal and plastic brackets with reference to materials, application, technology and biomechanics. J Orofac Orthop. 2002;63:113-28. 12- Graber TM. Orthodontics, current principles and techniques. St Louis: Mosby; 1985. 915 p.
13- Harzer W, Bourauel C, Gmyrek H. Torque capacity of metal and polycarbonate brackets with and without a metal slot. Eur J Orthod. 2004;26:435-41.

14- Kang B, Baek S, Mah J, Yang WS. Three-dimensional relationship the critical contact angle and the torque angle. Am J Orthod Dentofacial Orthop. 2003;123:64-73.

15- Kusy RP, Whitley JQ. Assessment of second-order clearances between orthodontics archwires and bracket slots via the critical contact angle for binding. Angle Orthod. 1999;69:71-80.

16- McLaughlin RP, Bennett JC. Bracket placement with the preadjusted appliance. J Clin Orthod. 1995;29:302-11.

17- McLaughlin RP, Bennett JC. The transition from standard edgewise to preadjusted appliance systems. J Clin Orthod. 1989;23:142-53.

18- McLaughlin RP, Bennett JC, Trevisi HJ. Mecânica sistematizada de tratamento ortodôntico. $1^{\text {a }}$ ed. São Paulo: Artes Médicas: 2002. 324 p

19- Meling TR, Odegaard J. The effect of second-order couple on the application of torque. Am J Orthod Dentofacial Orthop. $1998 ; 113(3): 256-62$

20- Meling TR, Odegaard J, Seqner D. On bracket slot height: a methodologic study. Am J Orthod Dentofacial Orthop. 1998; 113:387-93.

21- Miethke RR. Third order tooth movements with straight wire appliances. Influence of vestibular tooth crown morphology in the vertical plane. J Orofac Orthop. 1997;58:186-97.

22- Miethke RR, Melsen B. Effect of variation in tooth morphology and bracket position on first and third order correction with preadjusted appliances. Am J Orthod Dentofacial Orthop. 1999; 116:329-35.

23- Sadat-Khonsari R, Moshtaghy A, Schlegel V, Kahl-Nieke B, Möller M, Bauss O. Torque deformation characteristics of plastic brackets: a comparative study. J Orofac Orthop. 2004;65:26-33. 24- Sebanc J, Brantley WA, Pincsak JJ, Conover JP. Variability of effective root torque as a function of edge bevel on orthodontic arch wires. Am J Orthod. 1984;86:43-51.

25- Siatkowski R E. Loss of anterior torque control due to variations in bracket slot and archwire dimensions. J Clin Orthod. 1999;33:508-10.

26- Van Loenen M, Degrieck J, De Pauw G, Dermaut L. Anterior tooth morphology and its effect on torque. Eur J Orthod. $2005 ; 27: 258-62$.

27- Kapur-Wadhwa R. Physical and mechanical properties affecting torque control. J Clin Orthod. 2004;38:335-40.

28- Zachrisson BU. Buccal uprighting of canines and premolars for improved smile esthetics and stability. World J Orthod. 2006;7:406-12

29- Zanelato RC, Grossi AT, Mandetta S, Scanavini MA. Torque individualization for cuspids when the preadjusted appliance is used. Rev Clin Ortodon Dental Press. 2004;3:39-55

30- Zinelis S, Annousaki O, Eliades T, Makou M. Elementa composition of brazing alloys in metallic orthodontic brackets. Angle Orthod. 2004;74:394-9. 